Article

\title{
Integration of Wind Energy, Hydrogen and Natural Gas Pipeline Systems to Meet Community and Transportation Energy Needs: A Parametric Study
}

\author{
Shahryar Garmsiri ${ }^{1, *}$, Marc A. Rosen ${ }^{1}$ and G. Rymal Smith ${ }^{2}$ \\ ${ }^{1}$ Faculty of Engineering and Applied Science, University of Ontario Institute of Technology / 2000 \\ Simcoe St. North, Oshawa, ON L1H 7K4, Canada \\ ${ }^{2}$ Change Energy Services / 2070 Hadwen Road, Suite 101A, Mississauga, ON L5K 2C9, Canada \\ E-Mails: shahryar.garmsiri@uoit.ca (Shahryar Garmsiri); marc.rosen@uoit.ca (Marc A. Rosen); \\ rsmith@changeenergy.ca (Rymal Smith) \\ * Author to whom correspondence should be addressed; Tel.: +1-416-399-7779
}

Received: 03 September 2013 / Accepted: 09 October 2013 / Published: 01 November 2013

\begin{abstract}
The potential benefits are examined of the "Power to Gas" (P2G) scheme to utilize excess wind power capacity by generating hydrogen (or potentially methane) for use in the natural gas distribution grid. A parametric analysis is used to determine the feasibility and size of systems producing hydrogen that would be injected into the natural gas grid. Specifically, wind farms located in southwestern Ontario, Canada are considered. Infrastructure requirements, wind farm size, pipeline capacity, geographical dispersion, hydrogen production rate, capital and operating costs are used as performance measures. The model takes into account the potential production rate of hydrogen and the rate that it can be injected into the local gas grid. "Straw man" systems are examined, centered on a wind farm size of $100 \mathrm{MW}$ integrating a $16 \mathrm{MW}$ capacity electrolysis system typically producing $4,700 \mathrm{~kg}$ of hydrogen per day.
\end{abstract}

Keywords: hydrogen, natural gas, wind turbine, wind farm, NG pipeline, community, transportation, parametric study, straw man system. 


\section{Introduction}

Wind turbines (WTs), often clustered into wind farms, have proliferated in Ontario and many other regions across North America and in other countries in recent years for a variety of economic and environmental reasons. While potentially offering significant promise as a contributor to energy systems in the future, wind power has several problems. One is that it is highly intermittent, subject to significant changes in the level of power production over relatively short periods of time. Another problem is that the moment-by-moment supply of wind energy generally does not match to the varying demand of the power grid. These factors lead to times when the grid must either, a) accept power from wind farms at a loss, b) curtail production from less costly sources of power, or c) not accept the wind energy all together.

Several schemes have been proposed to mitigate these problems in order to improve the economic and environmental benefits of wind power installations. These schemes typically involve either applying the wind power to an immediate, local ("inside the gate") use, storing it in some form for later deployment, or converting it to a form that is needed by other markets.

One storage concept is to use electrolysers to store "excess" wind generated electricity as hydrogen. An electrolyzer is a device that uses electricity to split water molecules into oxygen and hydrogen. These gases are then stored for a variety of uses - such as feed stocks for industrial applications, or recombining them to regenerate electricity at a later time. Here, we consider the opportunities

associated with the concept of injecting wind-generated hydrogen into the natural gas distribution grid, essentially increasing the proportion of hydrogen that naturally occurs in natural gas. The concept of "wind to electricity to hydrogen to natural gas" is often referred to as "Power to Gas" (P2G).

P2G has the advantage of avoiding the need for large and expensive means to store or transport hydrogen; rather, it provides a readily available and potentially cost effective means to take the product to market. Below a certain concentration ( $\sim 20 \%$ hydrogen in natural gas) [Kippers 2011 ] hydrogen has no adverse effect on the combustion characteristics of natural gas and, in fact, its addition results in a cleaner burning fuel. P2G also relies on wind farms that are in close proximity to adequate and appropriate natural gas pipeline infrastructure; otherwise high transportation costs may be incurred. An economic disadvantage of $\mathrm{P} 2 \mathrm{G}$ can be that it effectively sets the monetary value of hydrogen equal to that of natural gas on a volumetric basis.

\subsection{Benefits of P2G to WT System Operators}

It is anticipated that a $\mathrm{P} 2 \mathrm{G}$ system may provide economic and operational benefits to WT system operators and others. Challenges, such as curtailing greenhouse gas production, stewardship of nonrenewable fuel resources, and energy security have driven the need to develop alternative sources of energy that are local, sustainable, and reduce impact on the environment. Wind power is considered to be plentiful, renewable, widely distributed, clean, zero greenhouse gas emitting during operation, and efficient in terms of land use [Fthenakis 2009]. Generally, its effects on the environment are usually less problematic than those from other power sources.

Hydrogen as an energy carrier, and as a means of energy storage, has the potential to increase the penetration and efficiency of sustainable energy sources such as wind and solar energy. The use of hydrogen can enable the large-scale use of hydro, solar, wind and geothermal energy, both for 
stationary and transportation energy systems. Preliminary studies have shown that it is possible to transport a mixture of natural gas and hydrogen through the existing natural gas network without pipeline modifications as long as the mass fraction of hydrogen remains sufficiently low [Castello 2005].

In this article, we consider the opportunities associated with the concepts of injecting hydrogen into the natural gas pipeline. By injecting hydrogen from surplus renewable electricity into the natural gas pipeline, the enormous transportation and storage capacity of the existing infrastructure can be used directly. Such an approach can make an important contribution to the transportation and storage of surplus or non-transportable renewable electricity. Injecting hydrogen into the natural gas network can contribute significantly to solving the problem of transporting and storing surplus electricity generated from renewable resources.

The concept of linking wind energy and hydrogen production using electrolysis is specifically examined in this article. Additionally, the electrolysis capacity associated with a wind farm size is compared to determine the daily maximum hydrogen production. A sensitivity analysis is performed for determining the variability costs associated with wind farm and electrolysis size. A simple payback period calculation is performed to determine the parameters that impact the outcome of the analysis.

\section{Background}

\subsection{Wind Farms}

Wind turbine designs are generally classified by the structure of the rotor and its location in the airflow [Teacher geek 2006]. The two main types of wind turbine are horizontal axis and vertical axis, with the most common configuration being the horizontal axis turbine. The rotor of a horizontal axis wind turbine rotates around a horizontal axis, parallel to the wind direction. The blades resemble propellers and are arranged rigidly in a plane that is always oriented perpendicular to the wind [Meyers 2013].

The installed capacity of wind turbines (WTs) has increased significantly since 2000. A study by the Canadian Wind Energy Association (CANWEA) in June 2013 indicated that the total capacity of WTs in Ontario is 2,043.2 MW [CANWEA 2013]. A wind farm is a group of WTs located in relatively close proximity, usually with a common tie in point to control electrical flow to the grid. A large wind farm ( 200 MW) may consist of several hundred individual wind turbines and cover an extended area; however the land between the turbines may be used for agricultural or other purposes. The full map of wind farms in southwestern Ontario as published by Ontario's Independent Electricity System Operator as of February 2013 [IESO 2013] can be accessed via the reference link.

While WTs offer the potential to deliver green energy for the future, they do have some inherent problems. One issue is that the driving force - the wind - is highly intermittent. The total power produced by a wind farm may change over relatively short periods of time. Also, occasionally there are times when the energy production rate exceeds the demand on the grid or the grid's capacity to transmit it. These factors lead to times when a) the grid can only accept power from wind farms at a loss, b) production from other less costly sources of power must be curtailed, or c) the energy must be foregone altogether. 


\subsection{Mitigation Strategies}

Several schemes have been proposed to mitigate the problems of intermittency and excess energy associated with wind farms in order to improve their economic and environmental benefits. These schemes typically involve either directing the wind power to an immediate, local ("inside the gate") use, storing it in some form for later deployment, or converting it to a form that can be directed to other markets.

There are several methods for directly or indirectly storing wind energy, such as thermal energy storage [ICAX 2007], mechanical energy storage (such as pumped water or compressed air) and chemical energy storage (such as hydrogen and batteries). Although the conventional battery appears to provide a readily available means of energy storage it is problematic for grid-scale electricity storage. At grid scales batteries are bulky, incur the expense of maintaining a large battery room, require sophisticated charge/discharge monitoring systems, and require thermal analysis and management to provide optimal battery life. Nevertheless, storing a limited amount of electrical power in batteries for short periods and then using it on site can be beneficial for on-site building or automotive loads.

\subsection{Hydrogen}

Another means of storing electricity is to use it to drive water electrolysis to generate hydrogen. This means of storage provides a great deal of flexibility. For instance, the hydrogen can be converted back into electricity via an internal combustion engine (ICE) or a fuel cell (FC), used either immediately or later, stored locally or shipped to an off-site location; and used in a wide variety of applications.

In electrolysis, water $\left(\mathrm{H}_{2} \mathrm{O}\right)$ is split into oxygen $\left(\mathrm{O}_{2}\right)$ and hydrogen $\left(\mathrm{H}_{2}\right)$, by passing an electric current through it [Carmo 2013]. Polymer Electrolyte Membrane (PEM) electrolysis provides a suitable means of generating hydrogen from renewable energy sources due to its fast response time, large operational range, relatively high efficiency, and the high purity of the gas generated (99.999\%).

A full electrolysis system requires a source of deionised water, temporary electrical storage, storage vessels, and compressors. PEM electrolyzers typically generate hydrogen at low pressures. High pressure electrolysis (HPE) requires more energy, but reduces the need for compression. The hydrogen produced may be stored in the immediate area, or be transported to off-site locations that have a use for hydrogen. In this case, local storage space and cost may be reduced, but a transport system would become necessary.

\subsection{Hydrogen Markets and Transportation Options}

It is desirable to use the hydrogen produced in high value applications such as vehicle fuel (in ICE or fuel cell vehicles), or as a feedstock in industrial applications such as food oil hydrogenation, gas turbine cooling, or steel making [Pressure Chemical 2013]. Most of these applications require a means to transport the hydrogen to the point of use.

Dedicated distribution pipelines for hydrogen are typically much more costly than natural gas pipelines. Some sources [Bromaghim 2010] estimate a cost of $\$ 1 \mathrm{M} /$ inch-mile as compared to the 
$\$ 300 \mathrm{~K} /$ inch-mile [Tubb 2012] for natural gas pipelines. Creating a new pipeline for hydrogen may be too expensive given the current market; however a dedicated network of hydrogen pipelines may become feasible if and when hydrogen becomes more widely used as an energy carrier.

Another means of transporting the hydrogen to market is via tube trailers (sometimes referred to as a pipeline on wheels). This method has recently been used successfully for transporting natural gas to off grid industrial locations. Several projects have been undertaken by Change Energy Services (CES) over the last three years, particularly in maritime Canada where the natural gas pipeline grid is relatively new and remote from much of the pre-existing industry. JD Irving, Heritage Gas, and Irving Oil have used this method to reduce energy costs and environmental emissions for customers requiring process heat for food processing, pulp paper mills, and other applications. Economic analysis conducted by CES for these customers indicates that in order to justify the capital cost of the compression, trailer, and end use decanting facilities, loads (in aggregate) on the order of 2,000 scfm of natural gas (equivalent to approximately $7,400 \mathrm{~kg}$ of $\mathrm{H}_{2}$ per day) are required [Smith 2013]. This much hydrogen could be supported by a wind farm of about $130 \mathrm{MW}$ but it would take some time to develop a market for this quantity of hydrogen (equivalent to about 7,000 hydrogen cars or 600 hydrogen buses).

Another option for using the hydrogen is utilization of the natural gas pipeline grid currently in place in most communities. This grid may offer a viable option by utilizing the hydrogen to augment the natural gas supply (essentially the $\mathrm{P} 2 \mathrm{G}$ solution), or as a means to transport it to a downstream separation facility. Downstream separation was explored in the NATURALHY project [NATURALHY 2006], as discussed later in this report.

Hydrogen produced by wind energy can also be converted to methane through a "methanation" process. Methanation processes are physical-chemical processes that generate methane from a mixture of various gases; the main components are carbon monoxide and hydrogen [Ponec 1978]. In this way the wind energy can be captured in a form that can be exported to other markets as natural gas.

\subsection{Power to Gas}

The concept of Power to Gas (P2G) proposes that "excess" wind energy be captured by using it to produce hydrogen, which can either be taken to market or used to augment the natural gas supply.

A power to gas unit (see Figure 1) receives its power from a nearby wind farm. The power drives the electrolysis equipment that transforms water into hydrogen which is injected into the regional gas transmission system. The hydrogen becomes part of the natural gas mix and can be used to generate power or heat.

Figure 1: Falkenhagen power-to-gas pilot plant [GlobeNewswire 2013].

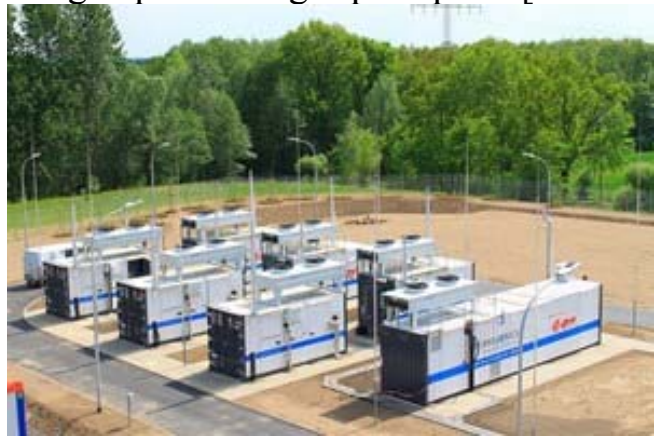


A recent article [Daily Fusion 2013] reported on the experience of E.ON in Falkenhagen Germany, injecting hydrogen produced with surplus wind energy into the natural gas system [E.ON 2013]. The region's wind farms already frequently produce more electricity than the local grid can handle. During a three hour test the unit produced 160 cubic meters (5,650 cubic feet) of hydrogen, which was injected into the natural gas pipeline system. This marked the first time E.ON successfully implemented all stages of the process, from receiving electricity to injecting hydrogen.

E.ON's P2G facility in Falkenhagen, Germany, uses wind power and an electrolyzer provided by Hydrogenics to split water molecules into hydrogen and oxygen. The hydrogen is injected into the existing regional natural gas transmission system. The hydrogen becomes part of the natural gas mix used in a variety of applications including space heating, industrial processes, mobility, and power generation. The facility's electrolyzer, which has a capacity of two megawatts is capable of producing up to 360 cubic meters of hydrogen per hour [GlobeNewswire 2013].

\subsection{Mixing Hydrogen with Natural Gas and Implications to the Infrastructure}

In examining a P2G delivery system's suitability for hydrogen there is a need first to investigate the extent to which existing assets, including the existing wind farm and natural gas pipeline infrastructure, can be used.

An existing natural gas system generally offers the following advantages:

- It is in place and available immediately

- It is well-established with existing grid management and operation strategies

- It is widely spread out and interconnected

- It has very high capacity, e.g., nearly 3 billion cubic feet per day in Ontario and Quebec [Energy source 2013]

- It has well-established safety procedures and an excellent safety record, based on a welldeveloped maintenance and control structure

- It has broad acceptance by the public

Existing natural gas transmission, distribution and end-use systems may be used, with suitable adjustments, for many mixtures of natural gas and hydrogen [Zhang 2009].

Hydrogen Enriched Natural Gas (HENG) is a mixture of hydrogen and natural gas. In theory, the two can be mixed in any proportion, but HENG typically has 10 to 20 per cent hydrogen by volume. At these concentrations, HENG is generally compatible with existing natural gas transmission and distribution infrastructure, as well as end-use equipment. Moreover, codes and standards in many jurisdictions treat HENG with less than 20 per cent hydrogen the same as natural gas. This can facilitate the initial deployment of HENG into many gas networks.

HENG offers important potential emissions and efficiency benefits, compared to natural gas. [World Energy 2012]. HENG enhances combustion and reduces $\mathrm{CO}_{2}$ emission from natural gas [Amrouche 2010], and reduces emissions of pollutants such as nitrogen oxide (NOx), carbon monoxide (CO) and unburned methane and other hydrocarbons. HENG can also improve the fuel efficiency of gas-fired combustion in boilers, engines and turbines, while still using existing natural gas delivery infrastructure and end-use equipment [Amrouche 2010].

Identifying the conditions under which hydrogen can be added without unacceptable consequences to natural gas, and the development of devices for hydrogen separation from a mixture, was an 
important part of the NATURALHY project [NATURALHY 2006]. The aims of NATURALHY were to test all the critical components of a system in which hydrogen was added to an existing natural gas network. NATURALHY also examined innovative technologies for separating the transmitted hydrogen for utilisation at end user sites [NATURALHY 2006].

Several studies have attempted to determine the appropriate mixture for HENG:

a) In the case of the E.ON project, it was shown that up to $10 \%$ hydrogen by volume can be injected into the pipeline [Daily Fusion 2013].

b) Other studies show that depending on the pipe material only up to $6 \%$ is allowable [HernandezRodriguez, G. et al.].

c) In ICEs, the addition of small amount of hydrogen to natural gas ( $5-30 \%$ by volume) leads to many advantages, due to physical and chemical properties [Ma 2008].

d) Below a of about $20 \%$ hydrogen in natural gas, hydrogen has no adverse effect on natural gas combustion characteristics and renders the fuel cleaner burning [Kippers 2011].

In summary the range of 5-20\% hydrogen in natural gas by volume in a pipeline appears to be feasible. However, for safety reasons when considering natural gas pipeline material embrittlement, and unknown end user applications, this study considers an upper limit of 5\% hydrogen by volume.

\subsection{Methanation}

Another method of injecting hydrogen into the natural gas pipeline that avoids material compatibility issues is to methanize the hydrogen prior to injecting it. Methanized hydrogen is also referred to as synthetic (or substitute) natural gas (SNG) [Zwart 2006].

Methanation is a physical-chemical process to generate methane from a mixture of various gases [Mignard 2003]. The main components required are carbon monoxide and hydrogen. The main chemical process in methanation (also known as Sabatier reaction) is as follows:

$$
\mathrm{CO}+3 \mathrm{H}_{2} \rightarrow \mathrm{CH}_{4}+\mathrm{H}_{2} \mathrm{O}
$$

In the methanation reaction, $\mathrm{CO}$ and $\mathrm{H}_{2}$ are converted to $\mathrm{CH}_{4}$ and $\mathrm{H}_{2} \mathrm{O}$ in a fixed bed catalytic reactor. Since methanation is highly exothermic, the increase in temperature is controlled by recycling the product gas or by using a series of reactors. Steam is added to the reaction to avoid coke formation in the reactor. The steam is then removed from the product gases by condensation [Mignard 2003].

A methanation facility requires water, process heat and cooling systems, and a source of $\mathrm{CO}$ (or $\mathrm{CO}_{2}$ ). As an example the Sabatier reaction process converts $\mathrm{H}_{2}$ and $\mathrm{CO}_{2}$ to SNG with water as a byproduct [Ch. Breyer 2011]. One example of SNG production is the SolarFuel GmbH plant in Germany [ETOGAS 2013]. SolarFuel, also known as ETOGAS, in collaboration with German research institutes, has successfully developed a method of using electricity to produce SNG using the surrounding air as a source of $\mathrm{CO}_{2}$. ETOGAS has built and run a successful test operating an alpha plant since 2009 which uses an electric load of $25 \mathrm{~kW}$ with an overall power-to-gas efficiency of $40 \%$ [Ali-Oettinlant 2012]. The ETOGAS SNG production plant utilizes an electrolysis reactor and a methanation reactor. The proposed Beta plant will use an Econamine FG plus $\mathrm{CO}_{2}$ capture process to supply the $\mathrm{CO}_{2}$ needed for methanation [Reike 2012]. 


\section{Problem Formulation and Analysis}

\subsection{Straw Man Model}

Table 1 below provides a list of parameters used to model the system for the purpose of this study. These parameters are used firstly as inputs to the cost and revenue model, and secondly for the sensitivity analysis. The sensitivity analysis is used to identify which parameters have the greatest impact on the outcomes of interest. Each parameter is represented by the letter "P" followed by a numerical value.

In the columns in Table 1, "min" represents the lowest value expected for the parameter, "max" the highest value expected, and "normal" the expected typical value. The latter is used as the baseline value in the present analysis. For example parameter "P2" is the Maximum Feed Factor (representing the highest input to the electrolyzer as a percentage of rated wind farm output). P2 is assigned a minimum value of $25 \%$ and a maximum value of $100 \%$, with a normal value of $50 \%$. Similarly "P3", represents the average wind energy provided by the wind farm (as a percentage of full operation at name plate rating). This parameter has a minimum value of $10 \%$; this minimum value refers to the lowest wind energy produced by the wind farm as a percentage of the wind farm capacity. It has a maximum value of $60 \%$, referring to the highest wind energy produced by the wind farm as a percentage of the wind farm capacity. Based information gathered by the Independent Electricity System Operator [IESO 2013] the actual capacity over the year as measured is nearly $30 \%$ of the total wind farm capacity. Therefore the normal value used is $30 \%$.

For parameters P2, P4, P8, P4, P15, P16, P21 and P22, a range was established that was broad enough to examine realistic economic feasibilities (for P21 and P22 we allow for the system owner to supply excess electricity at zero cost). The parameter P5 range is an estimate based on IESO data and P6 values are based on typical commercially available battery charge management systems. Parameters P9, P10, P11, P12, P13, P18, P19 and P20 were assigned ranges based on equipment and experience from previous CES projects. 
Table 1: Parameters used in the analyses.

\begin{tabular}{|c|c|c|c|c|c|}
\hline Parameter & Description & Units & Min. & Max. & Normal \\
\hline $\mathrm{P} 1$ & Wind farm (WF) size & MW & 25 & 200 & variable \\
\hline $\mathrm{P} 2$ & $\begin{array}{l}\text { Maximum feed factor (input power to } \\
\text { electrolyzer as a } \% \text { of WF size) }\end{array}$ & $\%$ & 25 & 100 & 50 \\
\hline P3 & $\begin{array}{l}\text { Average wind energy produced by WF } \\
\text { (as a } \% \text { of total size) }\end{array}$ & $\%$ & 10 & 60 & 30 \\
\hline $\mathrm{P} 4$ & $\begin{array}{l}\text { Battery feed rate (to provide short term } \\
\text { operational requirements of the } \\
\text { electrolyzer, as a } \% \text { of electrolyzer size) }\end{array}$ & $\%$ & 10 & 100 & 30 \\
\hline P5 & Electrolyzer full load supply duration & minutes & 10 & 60 & 30 \\
\hline P6 & $\begin{array}{l}\text { Battery charge range ( } \% \text { max charge - } \% \\
\text { min charge) }\end{array}$ & $\%$ & 50 & 90 & 70 \\
\hline $\mathrm{P} 7$ & Battery efficiency & $\%$ & 80 & 95 & 90 \\
\hline P8 & $\begin{array}{l}\text { Battery utilization (percentage of daily } \\
\text { energy produced by WF) }\end{array}$ & $\%$ & 5 & 30 & 25 \\
\hline P9 & WF controller efficiency & $\%$ & 90 & 99 & 98 \\
\hline $\mathrm{P} 10$ & WF transformer efficiency & $\%$ & 80 & 98 & 95 \\
\hline $\mathrm{P} 11$ & Electrolyzer rectifier efficiency & $\%$ & 70 & 95 & 85 \\
\hline $\mathrm{P} 12$ & $\begin{array}{l}\text { Electrolyzer hydrogen losses from } \\
\text { production }\end{array}$ & $\%$ & 5 & 20 & 10 \\
\hline $\mathrm{P} 13$ & Hydrogen storage losses & $\%$ & 0 & 5 & 2 \\
\hline $\mathrm{P} 14$ & $\begin{array}{l}\text { Power to run hydrogen handling and } \\
\text { metering system }\end{array}$ & $\mathrm{kWh} /$ day & 5 & 50 & 12 \\
\hline $\mathrm{P} 15$ & Power to run hydrogen dispensing unit & $\mathrm{kWh} /$ day & 5 & 50 & 12 \\
\hline $\mathrm{P} 16$ & Power to run water management system & $\mathrm{kWh} / \mathrm{m}^{3}$ of $\mathrm{H}_{2}$ & 0.0001 & 0.001 & 0.0005 \\
\hline $\mathrm{P} 17$ & Cost of water & $\$ / \mathrm{m}^{3}$ & 0.0001 & 0.001 & 0.0005 \\
\hline $\mathrm{P} 18$ & Electrolyzer maintenance cost & $\$ / \mathrm{kg}$ & 0.00001 & 0.0005 & 0.0001 \\
\hline P19 & $\begin{array}{l}\text { Compressor, purification, and storage } \\
\text { system maintenance cost }\end{array}$ & $\$ / \mathrm{kg}$ of $\mathrm{H}_{2}$ & 0.01 & 0.05 & 0.03 \\
\hline P20 & $\begin{array}{l}\text { Water management system maintenance } \\
\text { cost }\end{array}$ & $\$ / \mathrm{m}^{3}$ & 0.00001 & 0.0005 & 0.0001 \\
\hline $\mathrm{P} 21$ & Electricity cost & $\$ / \mathrm{kWh}$ & 0 & 0.12 & 0.00 \\
\hline $\mathrm{P} 22$ & Natural gas cost & $\$ / \mathrm{m}^{3}$ & 0 & 0.325 & 0.12 \\
\hline
\end{tabular}

Figure 2 shows the actual and median monthly contribution to the electrical power grid by wind farms in Ontario, based on an installed wind turbine capacity in southwestern Ontario of $\sim 1,500 \mathrm{MW}$ [IESO 2013], the data from this figure (summarized in Table 2). The actual production over the year as measured by the Independent Electricity System Operator [IESO 2013] is approximately 30\% of the total installed capacity. For this study, we have used an average value of $30 \%$ for calculations. 
Figure 2: Overall wind energy contributions from installed wind farms in Ontario [IESO 2013].

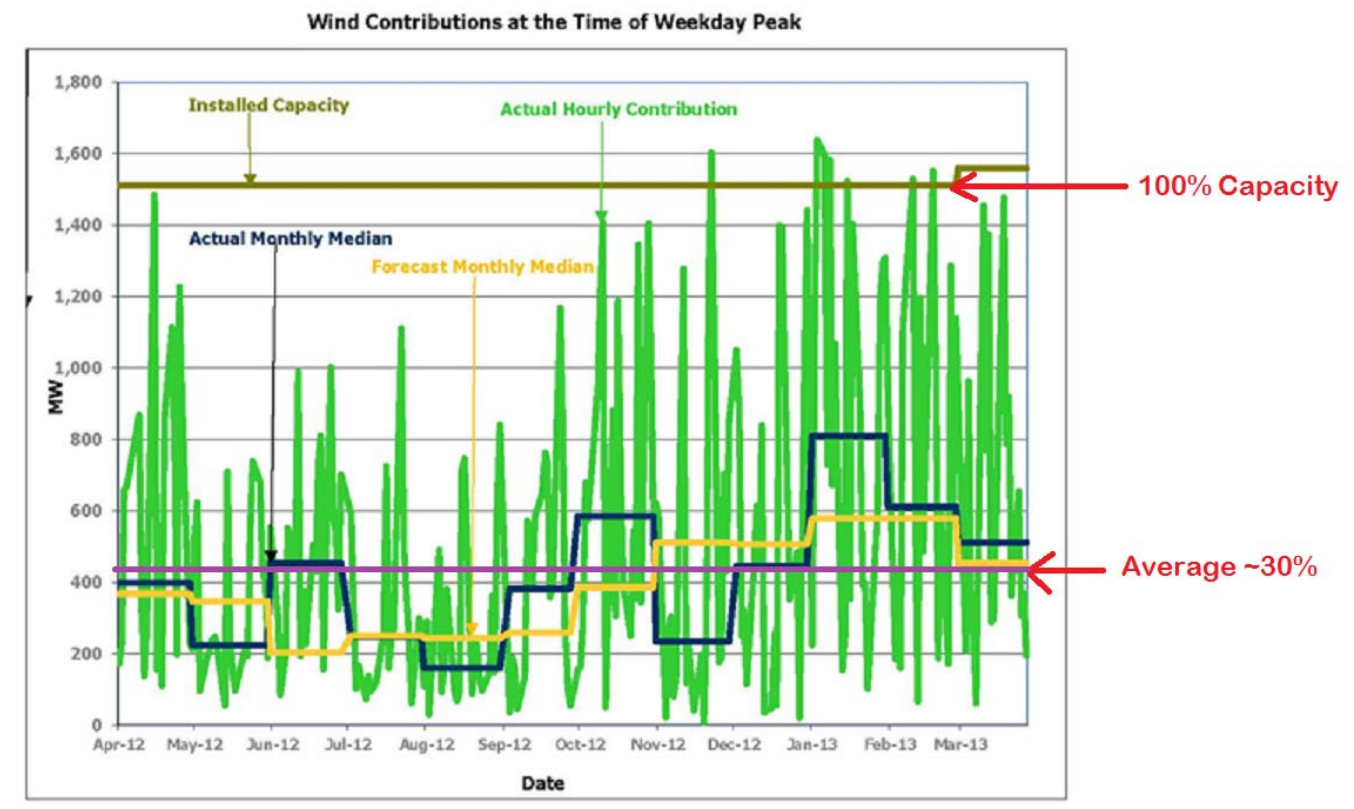

Note: A) Commercially operable capacity does not include commissioning unit. Therefore actual hourly contributions may exceed commercial capability. B) 100\% capacity means full name plate rating of installed and connected wind farms. C) "Contribution" refers to the amount of power supplied to the grid from the wind farms.

Table 2: Actual monthly median wind power produced [IESO 2013].

\begin{tabular}{|c|c|}
\hline Date & Actual monthly median power level (MW) \\
\hline April 2012 & 400 \\
\hline May 2012 & 220 \\
\hline June 2012 & 450 \\
\hline July 2012 & 250 \\
\hline August 2012 & 180 \\
\hline September 2012 & 390 \\
\hline October 2012 & 590 \\
\hline November 2012 & 220 \\
\hline December 2012 & 440 \\
\hline January 2013 & 800 \\
\hline February 2013 & 600 \\
\hline $\begin{array}{c}\text { March 2013 } \\
\text { over the year }\end{array}$ & 500 \\
\hline $\begin{array}{c}\text { Average wind power generation level } \\
\text { capacity }\end{array}$ & $\mathbf{4 2 0}$ \\
\hline $\begin{array}{c}\text { Total installed wind power generation } \\
\text { level compared to total installed wind } \\
\text { power generation capacity }\end{array}$ & $\mathbf{1 , 5 0 0}$ \\
\hline
\end{tabular}




\subsection{Sensitivity Analysis}

A sensitivity analysis examines how the output of a mathematical model or system varies according to the uncertainty of its inputs [Saltelli 2008]. Sensitivity analysis can be useful for a range of purposes [Pannell 1997], including:

- Testing the robustness of the model's results.

- Understanding relationships between input and output variables in a model.

- Identifying model inputs that cause significant uncertainty in the output.

- Simplifying the model. Inputs that have little or no effect can be removed

Only three sizes of wind farm are considered for the sensitivity analysis in this study (25 MW, 100 MW, and $200 \mathrm{MW}$ ). These sizes are used as they represent the range of typical wind farms found in locations closest to the major natural gas pipelines in southwestern Ontario. The model developed for this study could also be used for other wind farm sizes that may be of interest.

Tornado charts are used for presenting the sensitivity analysis results. Tornado charts are a type of bar chart where the data parameters (categories) are listed vertically instead of the standard horizontal presentation. The parameters are ordered based on their total relative impact, with the parameter having the greatest impact (longest bar) appearing at the top of the chart. The resulting chart has a final visual look resembling a tornado - hence the name.

Tornado charts are useful for deterministic sensitivity analysis, comparing the relative importance of the parameters under consideration. For each parameter considered, an estimate for the minimum, normal, and maximum value is made. The model is run with each variable at these three values while all other parameters are held at their "Normal" values [PMI 2013]. This allows for testing the sensitivity associated with each parameter.

Here, two types of sensitivity analysis are examined: the system cost per wind farm size, and the the simple payback period per wind farm size. The parameters outlined in Table 1 are used for this analysis.

Simple payback period (SPP) refers to the length of time required to recover the initial investment as calculated from operating costs and revenues. SPP is the least precise of all capital budgeting methods because the calculations in dollars are not adjusted for the time value of money [Kerzner 2009]. However, SPP is often used as a tool for analysis because it is easy to apply and understand, and makes no assumptions about how a business may choose to allocate debt or equity capital, or treat operating costs. A calculation of SPP is used with the tornado charts to determine the sensitivity associated with each parameter. 


\section{Results and Discussion}

In this section the parameters outlined in Table 1 are used to determine the rate of hydrogen production and cost of the $\mathrm{P} 2 \mathrm{G}$ system. The size of the electrolyzer system is evaluated as follows:

$$
\text { Electrolysis system size }(\text { ESS })=\text { max energy available } / 24 \text { hour/day }
$$

where the maximum energy available to the electrolyzer is calculated by:

$$
\text { Max energy available }(\mathrm{MEA})=(\mathrm{P} 1)(\mathrm{P} 2)(\mathrm{P} 3)(24 \text { hours/day })
$$

The rate of total hydrogen production per day is then determined from ESS and the known energy available from the wind farm. The energy efficiency of the water electrolysis process varies widely; reports suggest efficiencies of between 50-80\% [Zittel 1996, Kruse 2002]. These values refer only to the efficiency of converting electrical energy into hydrogen's chemical energy. Industrial electrolyzers used in past CES projects have required an electrical energy input of $65-80 \mathrm{kWh} / \mathrm{kg}$ of hydrogen produced. A value of $70 \mathrm{kWh} / \mathrm{kg}$ of hydrogen has been used as a typical value in this study. The rate of hydrogen produced per hour is obtained as follows:

$$
\text { Hydrogen produced per hour }=\operatorname{EER}(1000) /(24 * 70)
$$

where EER is the electrolyzer energy required, and MEA is the maximum energy available in the system. The EER is calculated via maximum energy available and subtracting the losses associated with the operation of the electrolyzer.

$$
\mathrm{EER}=\mathrm{MEA}-\mathrm{MEA}(1-\mathrm{P} 11)-[\mathrm{PPC}+\mathrm{EE}+\mathrm{PL}]
$$

where PPC is parasitic power consumption, EE is equipment efficiency, P11 is the electrolyzer rectifier efficiency, and PL is product losses.

Electrolysis system sizes and the rates of hydrogen production derived by the model for various wind farm sizes are provided in Table 3. Figure 3 presents the results shown in Table 3 graphically; estimates of electrolyzer size and $\mathrm{H}_{2}$ produced per day can be made for other wind farm sizes from this graph.

Table 3: Result summary table from analysis.

\begin{tabular}{|c|c|c|c|c|c|}
\hline $\begin{array}{c}\text { Wind farm } \\
\text { installed } \\
\text { power } \\
\text { generation } \\
\text { capacity } \\
\text { (MW) }\end{array}$ & $\begin{array}{c}\text { Maximum } \\
\text { energy available } \\
\text { (MEA) } \\
\text { (MWh/day) }\end{array}$ & $\begin{array}{c}\text { Electrolysis } \\
\text { system } \\
\text { capacity } \\
\text { (MW) }\end{array}$ & $\begin{array}{c}\text { Daily rate of } \\
\text { hydrogen } \\
\text { production } \\
\text { (kg/day) }\end{array}$ & $\begin{array}{c}\text { Hourly rate of } \\
\text { hydrogen } \\
\text { production } \\
\text { (kg/hr) }\end{array}$ & $\begin{array}{c}\text { Electrolyzer } \\
\text { energy } \\
\text { consumption } \\
\text { rate (EER) } \\
\text { (MWh/day) }\end{array}$ \\
\hline 25 & 99 & 4 & 1157 & 48.2 & 81 \\
\hline 100 & 396 & 16 & 4672 & 194.7 & 327 \\
\hline 200 & 792 & 32 & 9360 & 389.9 & 655 \\
\hline
\end{tabular}


Figure 3: Daily hydrogen production rate and electrolyzer capacity versus wind farm installed power generation capacity.

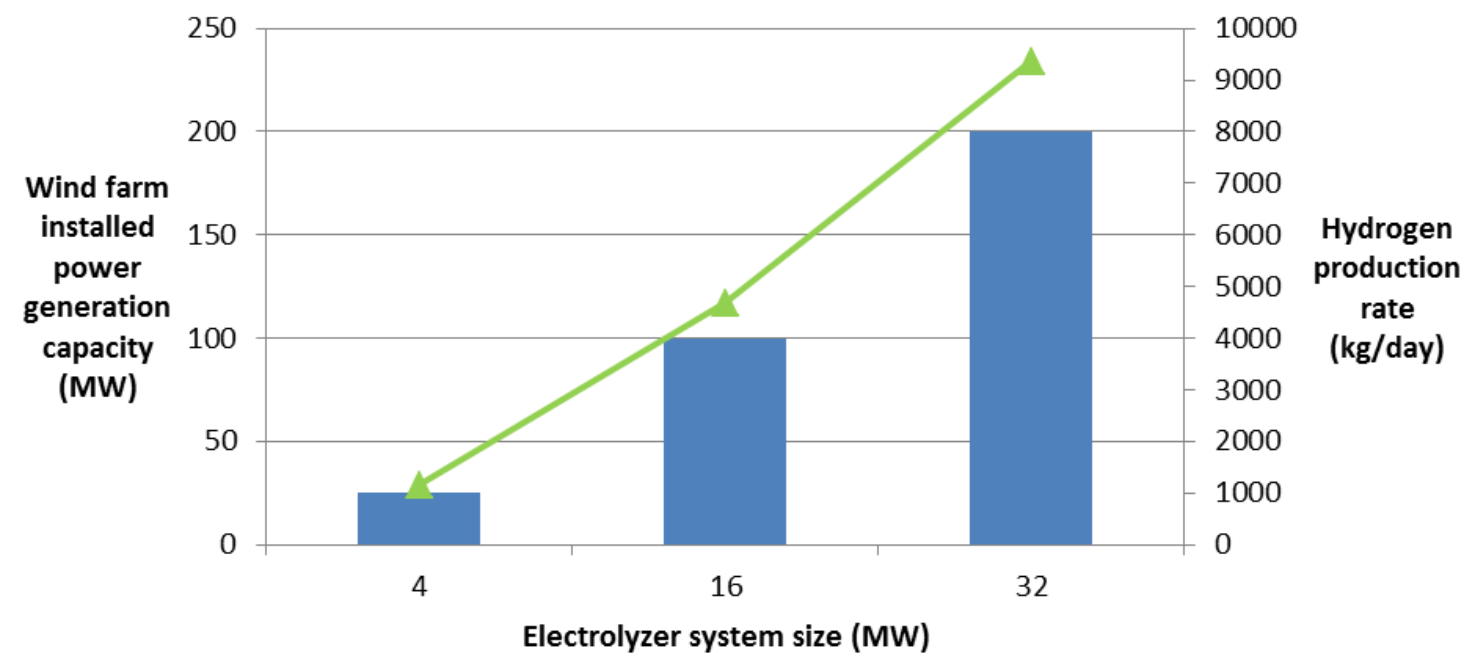

Wind farm installed power generation capacity $(\mathrm{MW})-$ Hydrogen production rate $(\mathrm{kg} / \mathrm{day})$

\subsection{System Costs and Sensitivity Analysis}

The system cost is determined as follows:

$$
\text { System cost }=\mathrm{PMC}+\mathrm{EC}+\mathrm{H}_{2} \mathrm{~S}+\mathrm{H}_{2} \mathrm{D}+\mathrm{ESC}
$$

where $\mathrm{PMC}$ is the power module cost, $\mathrm{EC}$ is the electrolysis system cost, $\mathrm{H}_{2} \mathrm{~S}$ is the cost of hydrogen storage, $\mathrm{H}_{2} \mathrm{D}$ is the cost of the hydrogen dispenser, and ESC is the electrical storage cost. These terms can be expressed as follows:

$$
\begin{gathered}
\mathrm{PMC}=\$ 250,000+\$ 10,000(\mathrm{ES}) \\
\mathrm{EC}=\$ 1,200,000(\mathrm{ES}) \\
\mathrm{H}_{2} \mathrm{~S}=\left(\mathrm{H}_{2} \mathrm{P}\right)(\$ 1,200 / \mathrm{kg})+\$ 335,000 \\
\mathrm{H}_{2} \mathrm{D}=\$ 190,000 \\
\mathrm{ESC}=\mathrm{SC}(1,000)(\mathrm{BPS}) \\
\mathrm{BPS}=30 \%(\mathrm{ES})(\mathrm{P} 5) / 60
\end{gathered}
$$

where BPS is battery pack size, $\mathrm{P} 5$ is the electrolyzer full load supply, ES is the electrolyzer size, $\mathrm{H}_{2} \mathrm{P}$ is the hydrogen produced per day, and SC is the storage (battery pack) cost. The value of SC is based on an estimate from a battery supply company. Note the listed numerical cost values in Equations 7 to 12 are estimates used by Change Energy Services based on prior projects.

The simple payback period (SPP) used in the sensitivity analysis is calculated as follows:

$$
\mathrm{SPP}=\text { System cost } / \text { Net revenue per year }
$$

Net revenue per year $=\mathrm{NVH}_{2}(365)$ 


$$
\begin{gathered}
\mathrm{NVH}_{2}=\mathrm{VH}_{2}-\mathrm{OC} \\
\mathrm{OC}=\mathrm{CE}\left(\mathrm{H}_{2} \mathrm{P}(70)\right)+\mathrm{H}_{2} \mathrm{P}(\mathrm{CMC})+\mathrm{EMC}\left(\mathrm{H}_{2} \mathrm{P}\right)+\mathrm{WPMC}(\mathrm{W})+\mathrm{P} 17(\mathrm{~W}) \\
\mathrm{VH}_{2}=(\mathrm{P} 22)\left(\mathrm{PH}_{2}\right)
\end{gathered}
$$

Here, SPP is the simple payback period, $\mathrm{NVH}_{2}$ is the net value of hydrogen, $\mathrm{VH}_{2}$ is the value of hydrogen, OC is the operating cost, $\mathrm{CE}$ is the cost of electricity ( $\$ \mathrm{MW}), \mathrm{CMC}$ is the compressor maintenance cost $(\$ / M W), E M C$ is the electrolyzer maintenance cost $(\$ / M W)$, WPMC is the water purification maintenance cost $(\$ / \mathrm{MW}), \mathrm{W}$ is the amount of water used, P22 is the cost of natural gas $\left(\$ / \mathrm{m}^{3}\right)$ and $\mathrm{PH}_{2}$ is the amount of hydrogen $\left(\mathrm{m}^{3}\right)$ injected into the natural gas pipeline. In this study, the hydrogen injected is based on the maximum of either the amount of the pipeline can accept $(5 \%$ of the natural gas pipeline flow is considered based on previous studies [Ma 2008]), or the amount of hydrogen the wind farm can produce. In most cases this is dictated by wind farm size.

The sensitivity analysis is conducted using Equations 6 and 13 and the "Min", "Normal", and "Max" values from Table 1. The "Normal" outputs are obtained by inputting all the "Normal" values into Equations 6 and 13. These values are used as the dividing point between the "Min" and "Max" values on the tornado charts. The equations are next evaluated based on each parameter's "Min" and "Max" value. The parameters are then sorted based on the absolute difference between the "Max" and Min" output values. The results are graphed with the highest difference value (or parameter with greatest impact) at the top.

Figure 4 displays the tornado chart for a system associated with a $25 \mathrm{MW}$ wind farm. In this chart the "Normal" system cost is $\$ 6,322,000$ and the following parameters have the greatest impact on the overall system cost:

- P3 - Average energy produced by the wind farm

- P2 - Maximum feed factor

- P4-Battery feed rate

- P5 - Electrolyzer full load supply duration

- P6 - Battery charge range 
Figure 4: $25 \mathrm{MW}$ wind farm system cost (\$).

$25 \mathrm{MW}$ wind farm system cost (\$)

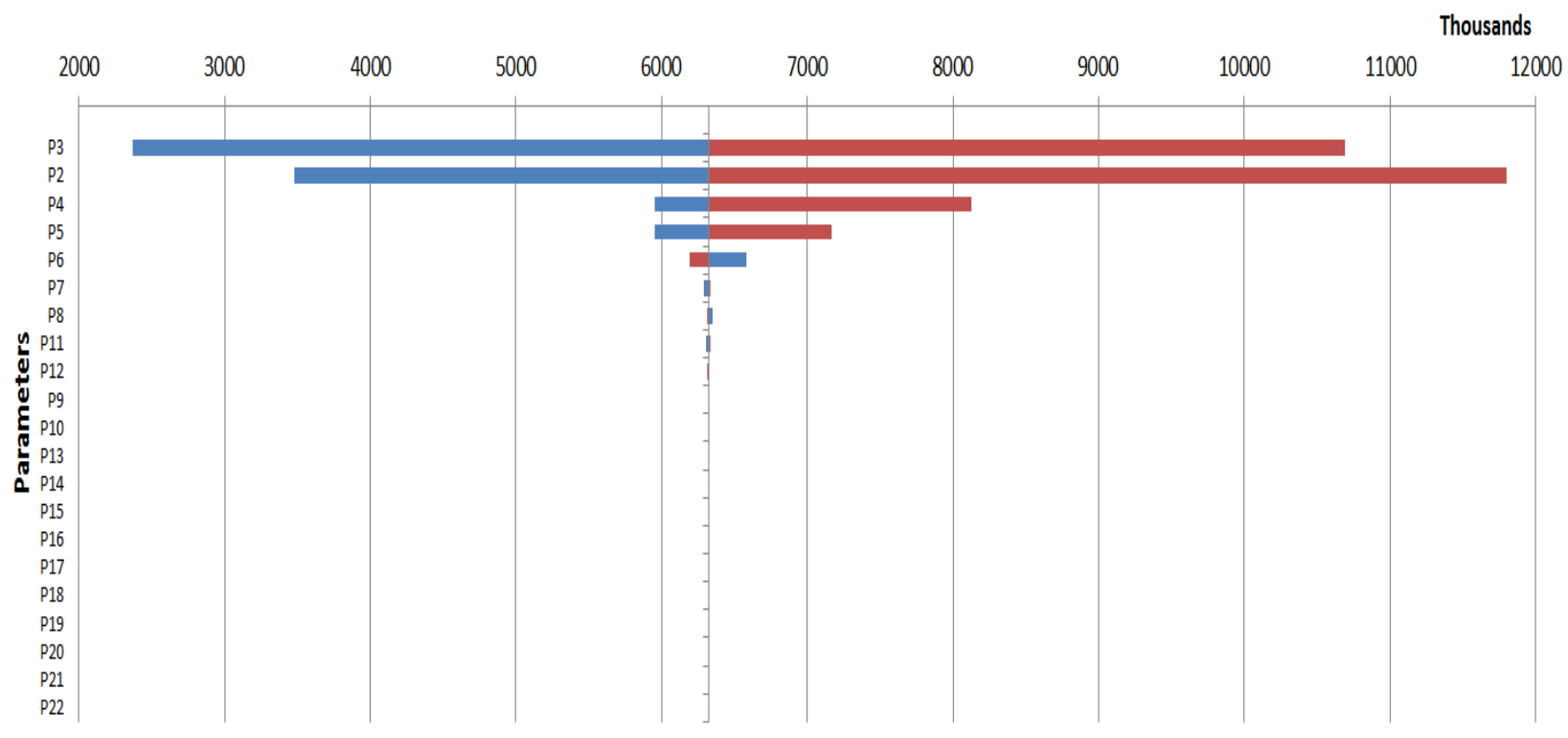

Figure 5 presents the tornado chart for a system associated with a $100 \mathrm{MW}$ wind farm. The "Normal" system cost in this case is on the order of $\$ 23,174,000$.

Figure 5: $100 \mathrm{MW}$ wind farm system cost (\$).

\section{$100 \mathrm{MW}$ wind farm system cost (\$)}

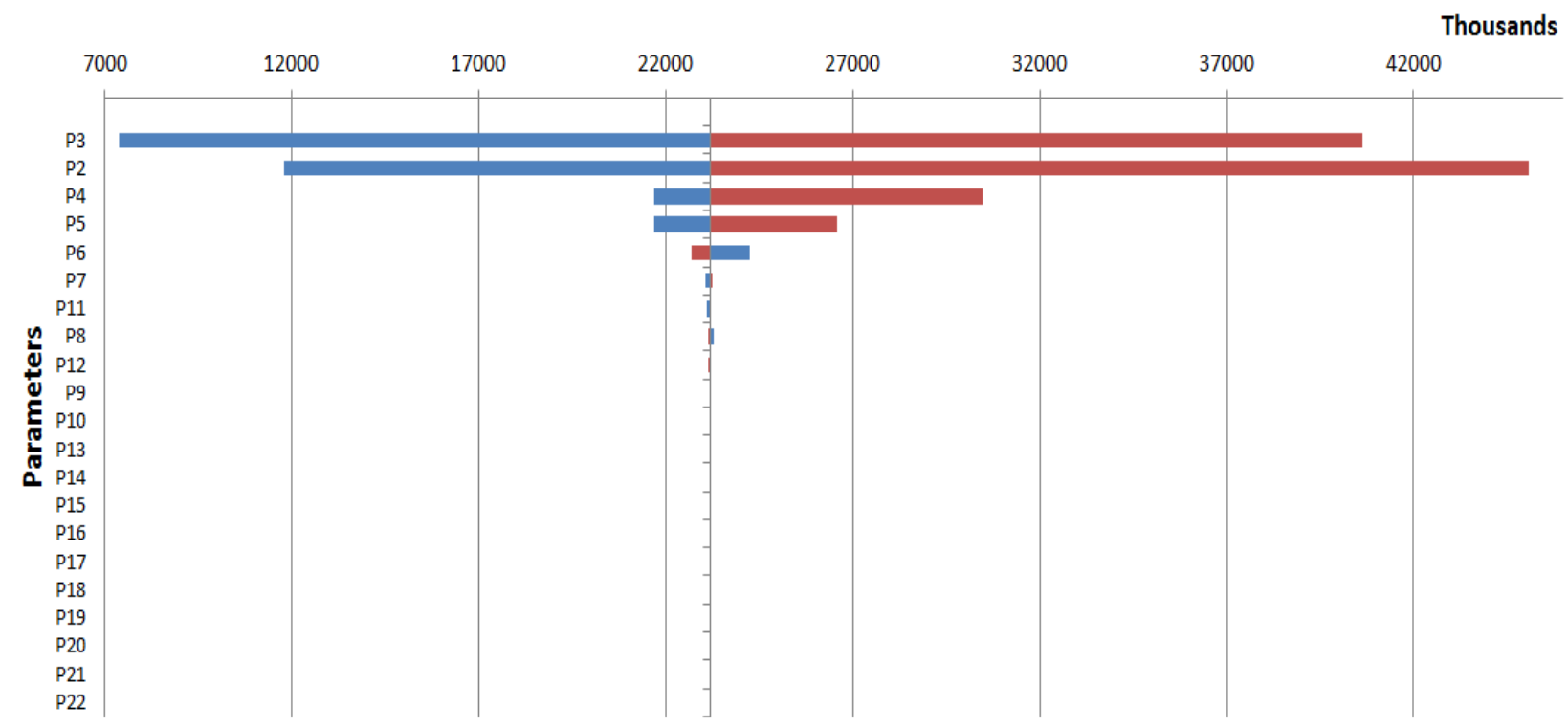

Figure 6 shows the tornado chart for a system associated with a 200 MW wind farm. The "Normal" system cost is $\$ 45,639,000$. Although prices vary for each wind farm, there is little variability in the relative impact of the parameters. This is because the total system cost is dominated by the cost of the electrolzer and battery packs. These values are relatively linear with respect to the wind farm size until the wind farm size drops below $5 \mathrm{MW}$. 
Figure 6: $200 \mathrm{MW}$ wind farm system cost (\$).

$200 \mathrm{MW}$ wind farm system cost (\$)

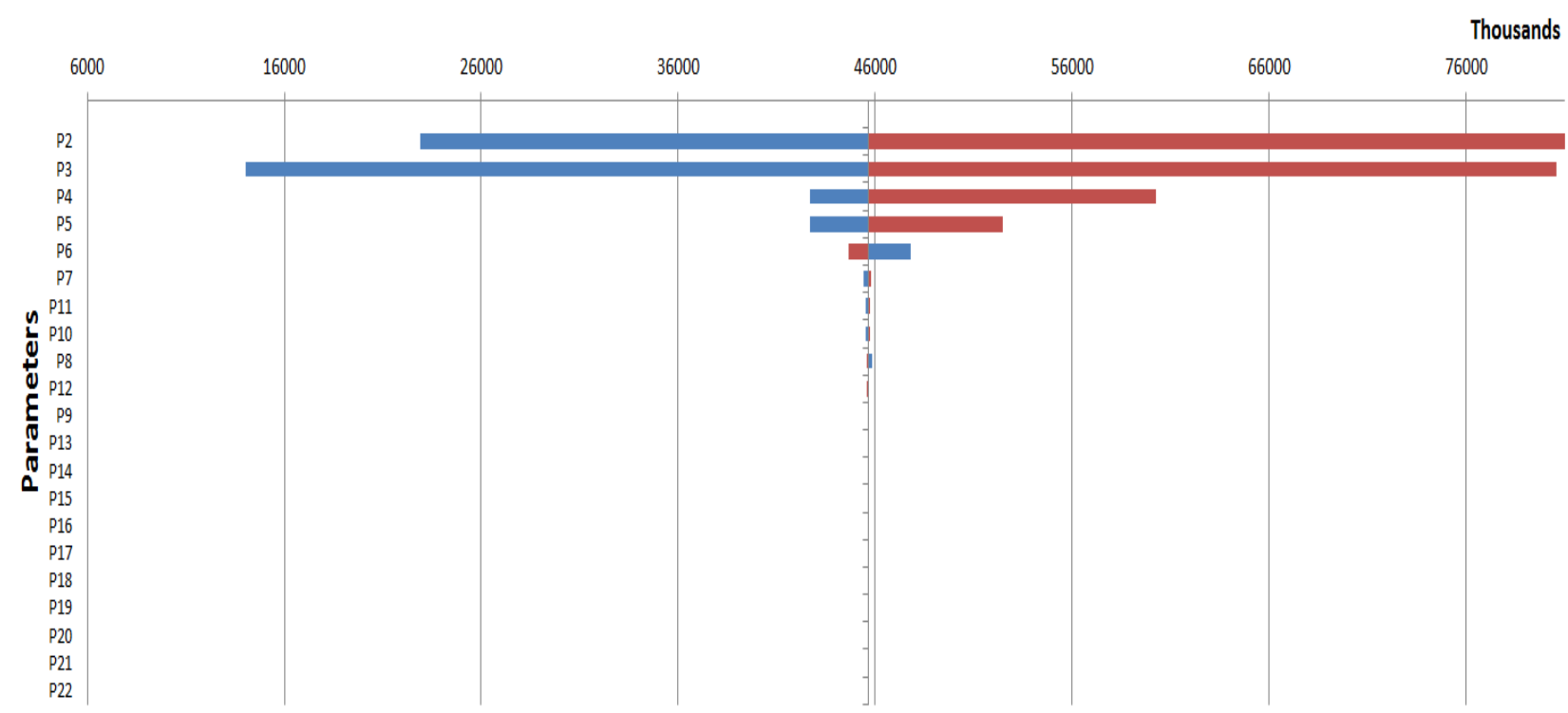

Figure 7 shows the tornado chart of the simple payback period for a system associated with a 25 MW wind farm. The "Normal" value derived is approximately 14.4 years. The parameters that have the greatest impact on the overall payback period are as follows:

P21 - Electricity cost

P22 - Natural gas cost

P4 - Battery feed rate

P3 - Average wind energy produced by wind farm

P11 - Electrolyzer rectifier efficiency

P5 - Electrolyzer full load supply duration

P2 - Maximum feed factor (to electrolyzer)

P12 - Electrolyzer hydrogen losses from production

P6 - Battery charge range

In the case of the electricity cost (P21), it is desirable to have a zero electricity cost. Any input electricity cost greater than approximately $\$ 0.005 / \mathrm{kWh}$ increases the payback period to greater than 30 years. On the other hand, it is desirable to have a higher value for the natural gas cost (P22). This is because the value of the hydrogen produced is fixed to the value of natural gas in the $\mathrm{P} 2 \mathrm{G}$ scheme. Therefore a higher price of natural gas increases the revenue generated from the hydrogen. 
Figure 7: $25 \mathrm{MW}$ wind farm simple payback period (years).

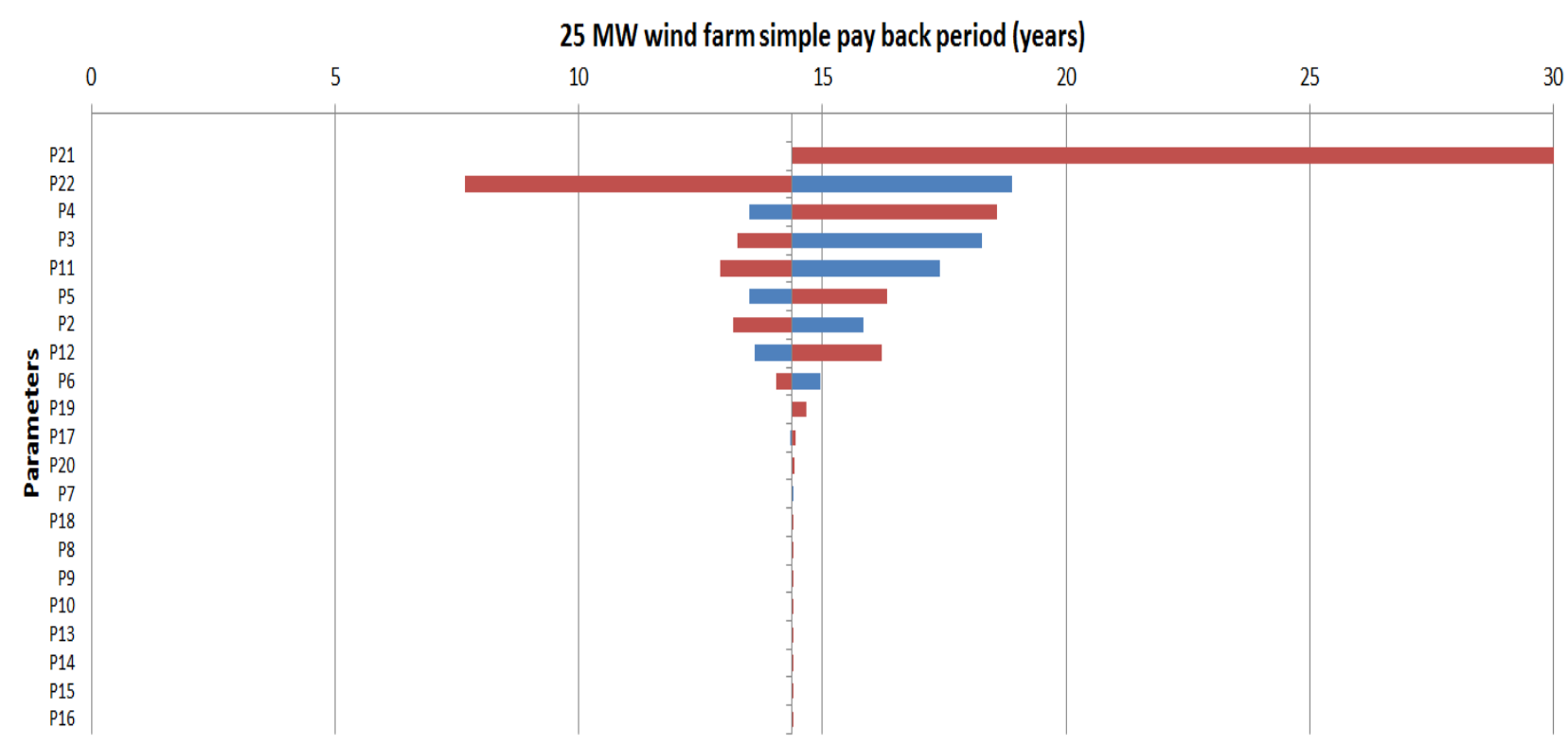

Figure 8 shows the tornado chart of the simple payback period for a system associated with a 100 MW wind farm. The "Normal" value derived is approximately 13.1 years.

Figure 8: $100 \mathrm{MW}$ wind farm simple payback period (years). $100 \mathrm{MW}$ wind farm simple pay back period (years)

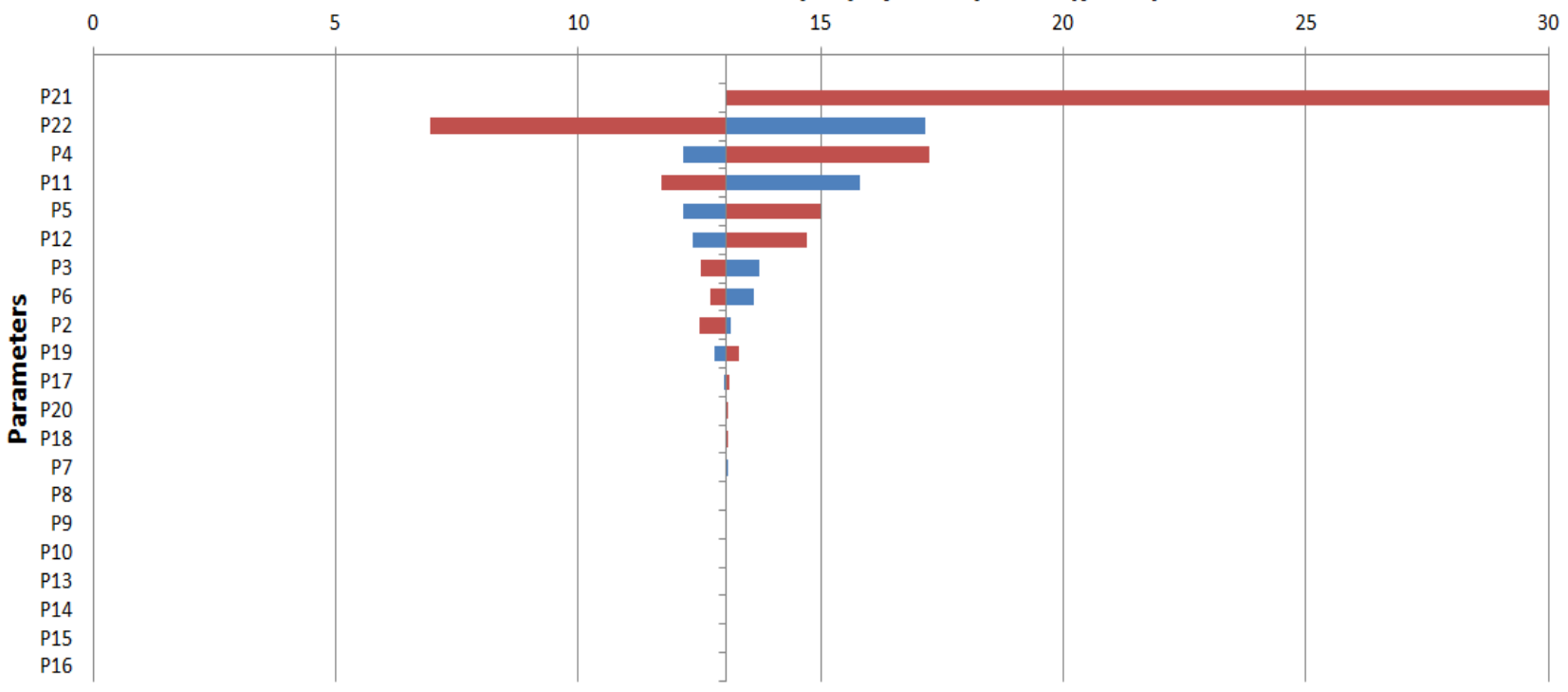

Figure 9 displays the tornado chart of the simple payback period for a system associated with a 200 MW wind farm. The "Normal" value derived is approximately 12.8 years.

In addition to the previous parameters, the efficiency of the wind farm transformer becomes a more significant factor for larger wind farms. The higher efficiency means more energy is available to the electrolyzer, resulting in greater hydrogen production and increased revenue, reducing the payback period. 
Figure 9: $200 \mathrm{MW}$ wind farm simple payback period (years).

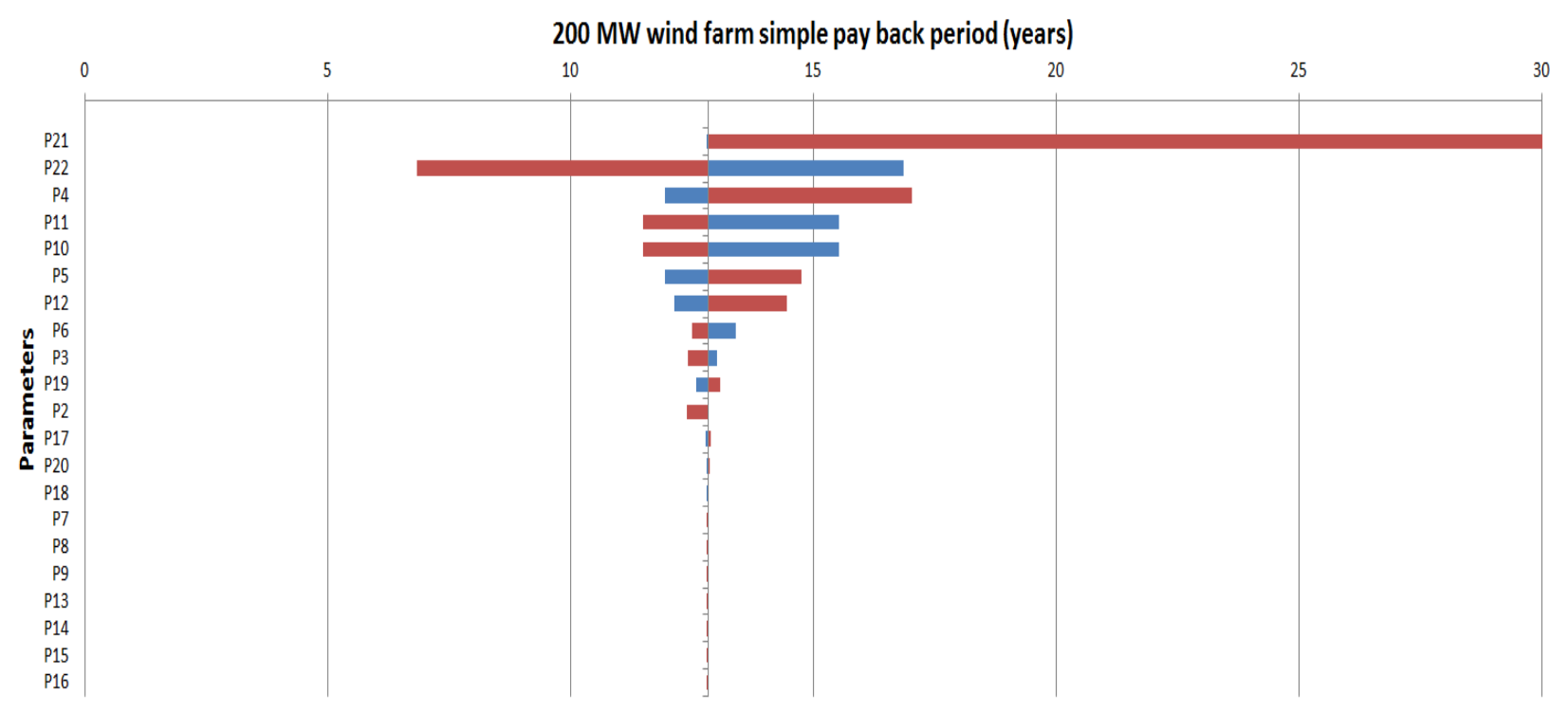

It is worth noting that the cost of natural gas used in the simple payback period sensitivity analysis is $\$ 3.50 /$ GJ [Ontario Energy Board 2013]. If the natural gas price is more comparable to German natural gas prices (averaging nearly $\$ 11.80 / \mathrm{GJ}$ over the past year) [Index Mundi 2013], then the payback periods using Equation 13, would be more acceptable: approximately 4 years for the $25 \mathrm{MW}$ wind farm, 3.5 years for the $100 \mathrm{MW}$ wind farm, and 3.45 years for the $200 \mathrm{MW}$ wind farm.

\section{Conclusions}

The benefits of utilizing hydrogen (via a P2G system) as a means to improve the economic performance of wind farms has have been examined. A parametric sensitivity analysis was prepared to determine the overall capital and operating costs of the P2G system and the simple payback period associated with each system was evaluated. Three wind farm power generating capacities were selected and analysed; $25 \mathrm{MW}, 100 \mathrm{MW}$, and $200 \mathrm{MW}$, reflecting the smallest to largest wind farms currently installed in Ontario.

Based on the sensitivity analysis, the simple payback periods for the $25 \mathrm{MW}, 100 \mathrm{MW}$ and 200 MW wind farms are 14.4 years, 13.1 years and 12.8 years respectively. Considering the large cost associated with the $200 \mathrm{MW}$ wind farm and comparing the simple payback periods, the $100 \mathrm{MW}$ wind farm is deemed to be the most likely choice for utilizing hydrogen in a P2G system.

\section{Acknowledgments}

The authors kindly acknowledge the financial support provided by the Natural Sciences and Engineering Research Council of Canada. 


\section{References and Notes}

Project Management Institute (PMI) (2013). A Guide to the Project Management Body of Knowledge (PMBOK Guide) (Fifth Ed.). Newtown Square, Pennsylvania, p. 338.

Ali-Oettinger, S. (2012). Aster Capital leads financing round for SolarFuel. Retrieved: October 2013, from: http://www.pv-magazine.com/news/details/beitrag/aster-capital-leads-financing-round-forsolarfuel_100008735/\#axzz2iTHd6pOJ.

Amrouche F., Benzaoui A., Erickson P., Mahmah B., Herouadi F., Belhamel M. (2010). Toward hydrogen enriched natural gas " $\mathrm{HCNG}$ " fuel on the Algerian road. International Journal of Hydrogen Energy 36, 4094-4102.

Bromaghim G., Gibeault K., Serfass J., Serfass P., Wagner E. (2010). Hydrogen and fuel cells: the U.S. market report. National Hydrogen Association (NHA), p. 6. Retrieved: July 2013, from: http://www.ttcorp.com/pdf/marketReport.pdf.

Canadian Wind Energy Association (CANWEA). (2013). Powering Canada's future, Canada's current installed capacity. Retrieved: June 2013, from: http://www.canwea.ca/pdf/Canada\%20Current\%20Installed\%20Capacity e.pdf.

Carmo M., Fritz D., Mergel J., Stolten D. (2013). A comprehensive review on PEM water electrolysis. International Journal of Hydrogen Energy 38, 4901-4934.

Castello P., Tzimas E., Moretto P., Peteves S. (2005). Techno-economic assessment of hydrogen transmission \& distribution systems in Europe in the medium and long term. Tech. rep., The Institute for Energy, Petten, Netherlands.

Ch. Breyer, S. R. (2011). Hybrid PV-Wind-Renewable Methane Powerplants - A potential cornerstone of global energy supply. In: 26th European Photovoltaic Solar Energy Conference, September 5-9 2011, Hamburg, Germany.

Daily Fusion, (2013). Green hydrogen injected into natural gas system for the first time. Retrieved: July 2013, from: http://dailyfusion.net/2013/06/green-hydrogen-injected-into-natural-gas-systemfor-the-first-time-11594/.

Energy source natural gas (2013). Midwest route to Ontario new threat to Western gas. Retrieved: July 2013, from: http://www.energysource.ca/our-company/latest-news-details.aspx? $\mathrm{id}=\mathrm{c} 33 \mathrm{~d} 3 \mathrm{~b} 3 \mathrm{e}-$ 411e-4aa0-a6ec-f47ae22ed82d.

E.ON, Power-to-gas unit injects hydrogen into natural gas system for first time. Germany. Retrieved: July 2013, from: http://www.eon.com/en/media/news/press-releases/2013/6/13/power-to-gas-unitinjects-hydrogen-into-natural-gas-system-for-f.html.

ETOGAS (2013). Alpha plant is in operation. Germany. Retrieved: October 2013, from: http://www.etogas.com/en/the-solution/the-alpha-plant-is-in-operation/

Fthenakis V., Kim H. C. (2009). Land use and electricity generation: A life-cycle analysis. Renewable and Sustainable Energy Reviews 13, 6-7.

GlobeNewswire (2013). Photo Release -- E.ON and Swissgas Begin Commercial Operations at Powerto-Gas Facility in Germany Using Hydrogenics Technology. Germany, Retrieved: October 2013, from: http://globenewswire.com/news-release/2013/08/29/570028/10046484/en/Photo-Release-E$\mathrm{ON}$-and-Swissgas-Begin-Commercial-Operations-at-Power-to-Gas-Facility-in-Germany-UsingHydrogenics-Technology.html. 
Hernandez-Rodriguez, G., Pibouleau, L., Azzaro-Pantel, C., Domenech, S. (2011). Impact of hydrogen injection in natural gas infrastructures. In: ESCAPE 21, 21th European Symposium on Computer-Aided Process Engineering (ESCAPE 21), May 29 - June 01, 2011, Chalkidiki, Greece . Independent Electricity System Operator (IESO) (2013). Ontario renewable energy (grid connected). Retrieved: August 2013, from: http://www.ieso.ca/imoweb/siteshared/images/wind_generation_in_Ontario.pdf.

Index Mundi (2013). Russian natural gas monthly price, USD per million metric British thermal unit. Retrieved: July 2013, from: http://www.indexmundi.com/commodities/?commodity=russiannatural-gas.

Interseasonal heat transfer ICAX (2007). Thermal Energy Storage - Seasonal Thermal Energy Storage using ThermalBanks ${ }^{\mathrm{TM}}$. Retrieved: July 2013, from: http://www.icax.co.uk/thermal_energy_storage.html.

Kerzner H. (2009). Project management, a systems approach to planning, scheduling, and controlling. John Wiley \& Sons. Hoboken, New Jersey, p. 614.

Kippers M.J., De Laat J.C., Hermkens R.J.M. (2011). Pilot project on hydrogen injection in natural gas on island of Ameland in the Netherlands. Paper presented at the International Gas Union Research Conference, Apeldoorn, The Netherlands.

Kruse B., Grinna S., Buch C. (2002). Hydrogen—status and possibilities. The Bellona Foundation report. http://www.bellona.org/filearchive/fil_Hydrogen_6-2002.pdf.

Ma F., Liu H., Wang Y., Li Y., Wang J., Zhao S. (2008). Combustion and emission characteristics of a port injection HCNG engine under various ignition timings. Internal Journal of Hydrogen Energy $33,816-822$.

Meyers, B. (2013). Types of wind turbines. Retrieved: July 2013, from: http://centurionenergy.net/types-of-wind-turbines.

Mignard D., Sahibzada M., Duthie J.M., Whittington H.W. (2003) Methanol synthesis from flue-gas $\mathrm{CO} 2$ and renewable electricity: a feasibility study. International Journal of Hydrogen Energy 28, 455-464.

NATURALHY. (2006). A NATURALHY project. Retrieved: June 2013 from: http://www.naturalhy.net.

Ontario Energy Board (2013). Natural gas rate updates, natural gas rates at a glance. Retrieved: July 2013, from: http://www.ontarioenergyboard.ca/OEB/Consumers/Natural+Gas/Natural+Gas+Rates.

Pannell D.J. (1997). Sensitivity analysis of normative economic models: Theoretical framework and practical strategies, Agricultural Economics 16, 139-152.

Pressure Chemical Company (2013). Catalytic hydrogenation processes. Retrieved: June 2013, from: http://www.presschem.com/hydrogenation.htm?sub id=3.

Ponec V. (1978). Some aspects of the mechanism of methanation and Fischer-Tropsch synthesis. Catalysis Reviews: Science and Engineering 18 (1), 151-171.

Rieke, S. (2012). Power-to-gas technology-the missing link in renewable energy systems. Pesented at Ecosummit Conference, Berlin, Germany. Retrieved: October 2013, from: http://ecosummit.net/uploads/eco12_230312_0930_stephanrieke_solarfuel.pdf.

Saltelli A., Ratto M., Andres T., Campolongo F., Cariboni J., Gatelli D., Saisana M., Tarantola S. (2008). Global Sensitivity Analysis. The Primer, John Wiley \& Sons, Chichester, West Sussex, England. 
Smith R. (2013). Pipeline-on-Wheels: Sustainability for off-pipeline high energy operations. Presented at Sustainability Applied, October 1-2, 2013, Mississauga, Ontario, Canada.

Teacher geek (2006). Type of wind turbines. Retrieved: July 2013, from: http://www.teachergeek.org/wind_turbine types.pdf.

Tubb R. (2012). 2012 pipeline construction report. Underground Construction. 68(8). Retrieved: July 2013, from: http://www.undergroundconstructionmagazine.com/2012-pipeline-construction-report.

World energy. (2012). Hydrogen-enriched natural gas bridge to an ultra-low carbon world. Paper by National Grid and Atlantic Hydrogen Inc. for gas industry executives, utility regulators, policy makers and administrators. Available at http://www.worldenergy.org/documents/congresspapers/225.pdf.

Zhang L., Adey R.A. (2009). Prediction of third party damage failure frequency for pipelines transporting mixtures of natural gas and hydrogen, in International Conference on Hydrogen Safety, September 16-18, 2009, Ajaccio-Corsica, France, Paper 155.

Zittel W., Wurster R. (1996). Production of hydrogen, from electricity by means of electrolysis. HyWeb: Knowledge - Hydrogen in the Energy Sector. Ludwig-Bölkow-Systemtechnik GmbH, Part 3.4. Retrieved: June from: http://web.archive.org/web/20070207080325/http://www.hyweb.de/Knowledge/w-i-energieweng3.html\#3.4.

Zwart R.W.R., Boerrigter H., Deurwaarder E.P., Van Der Meijden C.M., Van Paasen S.V.B. (2006). Production of Synthetic Natural Gas (SNG) from Biomass. Report for Energy Research Center of the Netherlands. Available at http://www.ecn.nl/docs/library/report/2006/e06018.pdf. 